\title{
TRANSFORMAÇÕES DO DIREITO E DESENVOLVIMENTO AGRÁRIO NA SOCIEDADE DE RISCO
}

\section{TRANSFORMATIONS OF AGRARIAN LAW AND DEVELOPMENT IN THE RISK SOCIETY}

\author{
João da Cruz Gonçalves Neto ${ }^{1}$ \\ Pedro Felippe Tayer Neto ${ }^{2}$
}

\begin{abstract}
RESUMO: O direito e o modelo de desenvolvimento agrário moderno passaram por profundas transformações desde o seu surgimento, nas sociedades industriais, até os dias de hoje. Novas tecnologias como os fertilizantes e pesticidas industriais e a manipulação genética trouxeram um grande aumento da produtividade no século $X X$, mas também a intensificação dos debates a respeito dos riscos da atividade agrária contemporânea. A proposta deste artigo é analisar algumas dessas transformações à luz das teorias a respeito da sociedade de risco, formuladas por Ulrich Beck e Anthony Giddens. No primeiro capítulo, serão expostos os traços fundamentais das sociedades de risco. No segundo, procurar-se-á expor como o direito e o desenvolvimento agrário se comportam nos cenários de risco. Para tanto, propõe-se uma abordagem qualitativa da bibliografia disponível a respeito do tema.
\end{abstract}

PALAVRAS CHAVE: desenvolvimento agrário; direito agrário; sociedade de risco.

\begin{abstract}
The Law and the modern agricultural development model have undergone profound changes since its inception, in industrial societies, to the presente days. New technologies such as industrial fertilizer and pesticides and the genetic manipulation brought a great increase in productivity in the twentieth century, but also the intensification of debates about the risks of contemporary agrarian activity. The purpose of this article is to analyze some of these changes in light of the risk society theories, formulated by Ulrich Beck and Anthony Giddens. In the first chapter, we will show the basic concepts of risk society. On the second, we will expose how the agrarian Law and development behaves in risk scenarios. Therefore, we propose a qualitative approach of the literature available on the subject.

\footnotetext{
${ }^{1}$ Doutor em Filosofia pela Pontifícia Universidade Católica do Rio Grande do Sul. Mestre em filosofia pela em Filosofia pela Universidade Federal de Goiás. Professor do programa de pós-graduação em Direito Agrário da Universidade Federal de Goiás (UFG). E-mail: dellacroce@dellacroce.pro.br

${ }^{2}$ Bacharel em Direito pela Universidade Federal de Uberlândia (UFU). Especialista em Direito Constitucional pela Universidade Federal de Goiás (UFG). Mestrando em Direito Agrário pela Universidade Federal de Goiás (UFG).E-mail: pedrotayer@yahoo.com.br
} 
KEYWORDS: Agrarian development; Agrarian law; risk society.

\section{CONSIDERAÇÕES INICIAIS}

As teorias a respeito da sociedade de risco vem promovendo um dos mais calorosos debates das ciências sociais nas últimas décadas. Segundo essas teorias, os riscos da atividade industrial das sociedades modernas vem sofrendo profundas transformações nas últimas décadas. De riscos limitáveis e identificáveis, capazes de afetar apenas grupos específicos de pessoas, típicos da atividade industrial moderna, esses riscos cresceram e se tornaram incalculáveis e imprevisíveis, capazes de prejudicar efetivamente toda a vida no planeta Terra. Se o desafio dos estudiosos das sociedades industriais modernas era entender como a riqueza era produzida e como era naturalizado o desigual processo de sua distribuição, nas sociedades de risco o desafio é entender a dimensão e as consequências dos riscos produzidos por essa nova configuração das forças produtivas.

Neste "cenário" de riscos, entender as transformações do modelo de desenvolvimento agrário (e consequentemente, do Direito Agrário) é importante para que se possa ter uma ideia dos desafios que vem sendo enfrentados nas últimas décadas. Progresso agrícola, desde o surgimento do capitalismo nos campos ingleses, vem sendo sinônimo de produtividade e lucratividade, ou seja, de aumento da quantidade de alimentos produzida e diminuição dos custos para essa produção. O Direito Agrário nasce corroborando este entendimento.

Para o constante aumento da produtividade, as sociedades industriais passam a desenvolver e incorporar novas tecnologias agrícolas, aumentando, ao mesmo tempo, os riscos envolvidos na produção. Em algum momento entre as décadas de 60 e 80 do século XX, pode-se afirmar que os riscos inerentes à produção agrícola deixam de ser aqueles riscos típicos das sociedades industriais modernas para tomarem os contornos das "mega ameaças" das sociedades de risco. O Direito Agrário passa a se preocupar não apenas com a 
produção, mas com o avanço constante da degradação ambiental, com a contaminação dos solos e dos lençóis freáticos por insumos agrícolas industrializados, com as fomes coletivas (SEN, 2010, p. 210) e a segurança alimentar, além dos riscos da biotecnologia.

Antes de buscarmos soluções para estes novos desafios do desenvolvimento agrário, é necessário entender como chegamos até aqui.

\section{I - A SOCIEDADE DE RISCO}

De acordo com Ulrich Beck (2010, p. 23-25), a sociedade contemporânea passou recentemente por uma mudança de paradigma, na qual, o mecanismo de distribuição dos riscos das atividades humanas é a peça fundamental para a compreensão.

Segundo a teoria, a modernidade nos Estados ocidentais significou um salto tecnológico e uma mudança profunda na organização do trabalho humano. Muito mais do que apenas novos meios de produção, como o arado, a máquina a vapor ou o microchip, essas novas tecnologias são apenas indicadores de um processo de mudança social muito mais profundo e que "reconfigura toda a trama social, no qual se alteram, em última instância, as da certeza das quais se nutre a vida" (BECK, 2010, p. 23).

A modernização nesses Estados ocorreu sob o manto de um poderoso argumento legitimador: o combate à miséria. Durante séculos a humanidade verdadeiramente "lutou contra as forças naturais" para conseguir prover o próprio sustento, e a industrialização passou a ser vista como a solução definitiva para a bonança. A sociedade industrial, assim, era caracterizada pela produção e distribuição de bens. Os riscos (potencial ocorrência de resultado indesejado) da produção desta riqueza existiam,todavia, eram locais, capazes de afetar apenas indivíduos ou grupos de indivíduos.

Como reitera Giddens (1991, p.17), esse lado "da oportunidade" do processo de modernização foi amplamente estudado pelos "pais fundadores" da sociologia. Marx acreditava que apesar das contradições internas que a luta REVISTA DO DIREITO UNISC, SANTA CRUZ DO SUL № $41 \mid$ p. 24 - 40| NOV - DEZ 2013 
de classes gerava no sistema capitalista, o prognóstico era da emergência de um sistema social mais justo. Durkheim "[...] acreditava que a expansão ulterior do industrialismo estabelecia uma vida social harmônica e gratificante, integrada através de uma combinação da divisão do trabalho e do individualismo moral" (GIDDENS, 1991, p. 17) e Weber criticava apenas que a expansão da produção de riqueza no regime capitalista era acompanhada de uma expansão no trabalho burocrático, que destruía a criatividade e a autonomia do ser humano.

A extensão do risco, o lado negativo da atividade industrial, sempre foi tratada como um assunto secundário pelos autores clássicos das ciências sociais. Marx, por exemplo, chegou a falar em falha metabólica, uma "[...] teoria da ruptura do metabolismo entre as sociedades humanas e a natureza, como resultado do produtivismo capitalista" (LÖWY, 2005, p. 26-27). A grosso modo, a lógica de produção capitalista levaria a um descompasso entre o aumento da produção humana, carente de recursos naturais, e o ritmo de restauração destes recursos naturais, ocasionando a destruição (alienação) do meio ambiente. Essa, entretanto, nunca foi a maior preocupação de Marx, que acreditava que seria a luta de classes a responsável pela derrocada capitalista.

O modelo de desenvolvimento que foi consagrado pela sociedade industrial prezava pela produção crescente de riquezas, ao mesmo tempo que empurrava os riscos e consequências da atividade para um plano secundário, no qual, em geral, se discutia a reparação monetária pelos danos ocasionados. Como mostra Ulrich Beck (2002, p.78), o sistema industrial criou os "cálculos de risco" para garantirem a continuidade da atividade industrial.

Não importava quão grande e extenso eram os danos, o próprio sistema encontrou uma forma de garantir a continuidade da produção frente à incerteza do futuro. Todo um sistema normativo foi produzido para que cálculos de risco se tornassem apólices de seguros, calculadas com base em "taxas de sinistro" ou de compensação, sempre partindo da premissa de que os danos poderiam ser sanados com dinheiro. Segundo Beck (2002, p. 82), tratava-se de uma "aliança social contra os perigos e danos produzidos industrialmente", baseada em uma rede de seguros públicos e privados que pretendiam conter e distribuir adequadamente as consequências da revolução industrial. 
A tese central da obra de Beck (2002, p.82-83) é que em meados do século XX houve uma subversão dessa lógica de distribuição dos riscos da atividade industrial, o que pode ser percebido em uma série de "desafios tecnológicos", como a energia nuclear, as produções de compostos químicos, biotecnológicos e genéticos e a contínua degradação ambiental. Pela primeira vez na história, as decisões tomadas pelas instituições da sociedade industrial possuíam força para destruir toda a vida na Terra ${ }^{1}$. Essa possibilidade, na visão de Beck, é o que efetivamente distingue a época em que vivemos da modernidade industrial.

Se o que caracterizava a sociedade industrial era a produção de bens para prover as necessidades humanas, e o desafio era entender como ocorria a naturalização da distribuição desigual, na sociedade de risco o desafio é entender a extensão e a proporção dos riscos gerados pela produção de riquezas, assim como as suas consequências. Como afirma Beck (2010, p. 2627), os perigos das forças produtivas na sociedade de risco "[...] suspendem os fundamentos e categorias nos quais nos apoiávamos até então para pensar e agir - espaço e tempo, trabalho e ócio, empresa e Estado nacional, até mesmo as fronteiras entre blocos militares e continentes."

A natureza destes "megaperigos" invalida completamente as medidas paliativas e de segurança que foram formuladas durante a sociedade industrial. Os danos oriundos destes novos riscos são ocasionados pela conjugação de uma série de fatores (o que na maioria das vezes impossibilita a imputação de responsabilidade a um grupo de agentes), assim como se prolongam pelo tempo e pelo espaço. Como representar em termos monetários os danos causados pelo despejo excessivo de gases tóxicos na atmosfera? Talvez seja possível quantificar o prejuízo para as populações próximas em um curto espaço de tempo, mas é possível quantificar o prejuízo para todo o globo? Como quantificar a contribuição para o efeito estufa, para o degelo das calotas polares ou para a aceleração das mudanças climáticas? E ainda, como entender todos os desdobramentos desta ação prolongados no tempo? Após quantos anos os gases emitidos deixarão de afetar o globo? A dificuldade em responder a questõescomo essas ajudam a expor a extensão da complexidade dos novos riscos da atividade industrial. 
E ainda, nenhuma instituição humana da atualidade está preparada para o caso "do pior acidente imaginável" (BECK, 2002, p.83). Não existem medidas paliativas que possam conter, ou seguros que possam arcar com os danos de um acidente nuclear de larga escala. O que está em risco, agora, é a própria existência de vida na Terra.

Ulrich Beck (2010, p. 27-28) expõe a sua teoria a respeito da sociedade de risco em cinco teses. De acordo com a primeira, os riscos produzidos pelo "estágio mais avançado das forças produtivas" são distintos das riquezas. Esses riscos desencadeiam danos "sistematicamente definidos" e muitas vezes invisíveis (como os poluentes no ar, a radiação ou as toxinas no solo). Graças a essa invisibilidade dos danos, esses riscos acabam se curvando a "processos sociais de definição", uma vez que sua potencialidade lesiva é definida justamente pelos conhecimentos científicos que são elaborados a respeito deles. Assim, neste processo de interpretação dos danos, eles "[...] podem ser alterados, diminuídos ou aumentados, dramatizados ou minimizados no âmbito do conhecimento [...]" (BECK, 2010, p. 27).

A segunda tese é de que os riscos desta sociedade, cedo ou tarde,atingem aqueles que os produziram ou que lucraram com eles, apesar de inicialmente serem distribuídos de acordo com posições em classes ou extratos sociais. "Eles contêm um efeito bumerangue, que implode o esquema de classes" (BECK, 2010, p. 27). Além disso, os riscos não obedecem às estruturas dos Estados nacionais. A atividade poluidora de um Estado certamente afetará a natureza de outro, o que acaba empurrando os Estadosa acordos internacionais.

Apesar disso, os riscos não ameaçam a lógica de desenvolvimento capitalista. A teorda terceira tese, os próprios riscos se tornam uma grande oportunidade de negócios. "Eles são as necessidades insaciáveis que os economistas sempre procuraram[...], os riscos civilizatórios são um barril de necessidades sem fundo, interminável, infinito, autoproduzível (BECK, 2010, p. 28)."

O conhecimento a respeito do risco, nestas sociedades, adquire nova relevância política. Nas sociedades industriais tradicionais, a existência dos 
riscos irá determinar a consciência das camadas sociais a respeito de prevenção e reparação. Já nas sociedades de ameaça, os riscos são tão extensos e presentes em cada segmento da vida das pessoas que a tendência é se tornarem invisíveis. Desta forma, conforme a quarta tese de Beck (2010, p. 28), é a consciência das pessoas a respeito da existência dos riscos que irá determinar sua própria existência.

A quinta e última tese exposta por Ulrich Beck versa a respeito do "potencial político das catástrofes". Decisões que anteriormente eram tipicamente gerenciais e estavam restritas ao âmbito das empresas tornam-se objeto de discussões por toda a sociedade. O manejo e a responsabilização dessa nova forma de risco "podem acabar envolvendo uma reorganização do poder e da responsabilidade" (BECK, 2010, p. 28). As causas do risco, ou seja, o próprio processo de modernização, deixam de ser apolíticos e se tornam um tema eminentemente político.

De todas as transformações sentidas nas sociedades de risco, a que provavelmente exerceu a maior influência sobre os rumos do desenvolvimento agrário foi a superveniência dos "sistemas peritos" (expert systems). $\mathrm{Na}$ definição de Anthony Giddens (1991, p. 37-38), trata-se de "sistemas de excelência técnica ou competência profissional que organizam grandes áreas dos ambientes material e social em que vivemos hoje".

A ideia central dos sistemas peritos é a confiança. De acordo com o exemplo daquele mesmo autor (GIDDENS, 1991, p. 38), ao entrar em um avião, a maioria das pessoas possui um conhecimento no máximo rudimentar a respeito de como a máquina funciona, entretanto, todas essas pessoas possuem uma "fé", uma confiança, de que os riscos imanentes àquela atividade foram reduzidos ao máximo pelos peritos que participaram de sua elaboração. Mesmo sem saber como um avião pode voar, as pessoas em geral tendem a confiar em quem sabe. "Há um elemento de pragmático na fé, baseado na experiência de que tais sistemas geralmente funcionam como se espera que eles o façam" (GIDDENS, 1991, p. 39).

Esses sistemas, em primeiro lugar, criam formas de distribuição dos conhecimentos técnicos e profissionais de forma "impessoal", e, em um 
segundo momento, criam formas de avaliar se os profissionais que se colocam como portadores destes conhecimentos efetivamente tem competência para exercê-los. Tratam-se de provas para averiguar conhecimentos científicos e de instituições sociais voltadas à fiscalização do emprego destes conhecimentos, tais como as fiscalizações sobre a produção de automóveis, os conselhos de fiscalização de atividade profissional ou simplesmente a crítica pública.

Foram esses sistemas, graças à ampla confiança pública de que gozam, que permitiram à sociedade industrial moderna a confecção dos "cálculos de risco" e a sua utilização em um sistema de seguridade social. Ainda que não tenha grandes conhecimentos a respeito da legislação e da teoria econômica envolvida, o cidadão quando compra um seguro para sua casa ou para o seu carro acredita que o valor que pagoufoi baseado em uma "taxa de sinistro", e que essa, por sua vez, determina o preço justo proporcionalmente à probabilidade (risco)da ocorrência de dano, considerando medidas paliativas tomadas pelo segurado. Esse sistema, entretanto, perde sua lógica nas sociedades de risco.

No caso dos "mega perigos" nucleares, biológicos, químicos, genéticos e ambientais, como adverte Ulrich Beck (2002, p. 84), os pilares do cálculo do risco são invalidados devido à três fatores. Em primeiro lugar, esses cálculos não levam em consideração o dano global, que geralmente é irreparável e impossível de se limitar, demonstrando a falência da monetarização do dano e do binômio dano-reparação, essencial às sociedades industriais. Em segundo, os perigos agora são fatais. Não há, assim, como confiar nas "medidas paliativas ou cautelares" e nos "controles antecipados de danos". Nos casos de acidentes nucleares a assertiva é especialmente visível. E, em terceiro lugar ${ }^{2}$, o acidente perde a sua definição no tempo e no espaço, tornando-se um evento com início mas sem um fim. Isso significa a abolição dos padrões de normalidade, e, consequentemente, dos mecanismos de avaliação dos riscos que são a base dos cálculos do perigo.

Todavia, ao contrário do que se poderia imaginar, a implosão dos mecanismos de cálculo de risco não enfraquece os sistemas peritos. Como diz Beck (2002, p. 84), as medidas paliativas ou cautelares, que garantiam alguma estabilidade social, vão dando lugar ao dogma da infalibilidade da ciência 
(eldogma de la infalibilidad tecnológica). Até que o próximo dano ocorra, os peritos estão corretos. Segundo o autor, da mesma forma, a imprevisibilidade dos resultados danosos, ao invés de ampliar as hipóteses de responsabilização, acaba reduzindo-as, em uma "irresponsabilização" geral pelas consequências dos riscos tomados. O exemplo (BECK, 2002, p. 85) levantado pelo autor é brutal: de 21.000 casos de crimes ambientais instruídos na Alemanha em 1996, houveram apenas 49 condenações ao cárcere, das quais 31 foram suspensas. Apesar dos riscos nestas sociedades serem mais amplos, complexos e prolongados no tempo, a aplicação do nexo de causalidade (causalidad) torna-se cada vez mais estrita.

Este é o "ambiente" do desenvolvimento agrário, e, por consequência, do direito agrário da atualidade: um modelo de valorização dos sistemas peritos (amparados pelo dogma da infalibilidade científica) e de irresponsabilização dos agentes tomadores de riscos e causadores de danos.

\section{II - DIREITO E DESENVOLVIMENTO AGRÁRIO NA SOCIEDADE INDUSTRIAL E NA SOCIEDADE DE RISCO}

A caça, a coleta e, posteriormente, a agricultura e a criação de animais acompanharam o ser humano desde o seu surgimento. Nas mais antigas legislações conhecidas existem relatos de normas versando sobre o trabalho no cultivo do solo e a "propriedade" dos animais. De normas simples e bem definidas, como é o caso do Código de Hamurabi $^{3}$ (de aproximadamente 1.700 a.C.), até normas extremamente complexas e de extenso impacto social, como a Lei das Sesmarias portuguesa (promulgada no ano de 1.375), a produção de alimentos sempre esteve presente no Direito. Não se pode, entretanto, identificar a existência de um ramo autônomo de direito agrário com a mera existência de legislação com tal conteúdo.

O nascimento do direito agrário, como ramo autônomo, é recente, e tem como marco a fundação da Rivista de Diritto Agrario, no ano de 1922, na Itália (MANIGLIA, 2009, p.30). Tratou-se de uma compilação dos principais escritos 
sobre o tema,organizado por Giangastone Bolla, pai do direito agrário "moderno". Até a fundação da revista, o entendimento acadêmico sobre a legislação agrária estava intrinsecamente ligado à tradição civilista francesa, dando ênfase aos contratos e especialmente à propriedade privada. $\mathrm{Na}$ clássica (e ultrapassada) distinção entre direito público e privado, a comunidade acadêmica inclinava-se em classificar o agrário como um ramo do direito privado, com algumas especificidades.

Como apurou Trentini (2012, p.2), a corrente teórica inaugurada por Giangastone Bolla ganhou notoriedade no meio acadêmico por ter passado a defender uma concepção de direito agrário bastante distinta. Em primeiro lugar, a atividade agrária não poderia ser diminuída a apenas o estudo dos contratos, uma vez que se trata de um fenômeno não apenas econômico, mas de profundo cunho e influência social. E, justamente por este motivo, não seria adequado estudá-lo exclusivamente dentro do ramo do direito privado, uma vez que também possuiria características de direito público, estando em um meio termo entre as duas classificações.

Antonio Carrozza e Ricardo Zeledón (1990, p. 139), dois notáveis agraristas, entendem que naquele momento o agrário deixava de ser um mero conjunto normativo para efetivamente conquistar o título de "ciência", e que isso só foi possível graças à confluência de uma série de fatores econômicos, sociais e políticos, afirmando, ainda, que o direito agrário é eminentemente um direito histórico.

Os fatores que propiciaram o surgimento do direito agrário como um ramo autônomo são conhecidos: o capitalismo, a ruptura da rigidez e da unidade do direito privado e a evolução dos modelos constitucionais de ordenamento jurídico (CARROZZA; ZELEDÓN, 1990, p. 141).

O capitalismo porque artificialmente separou a terra do capital e do trabalho, transformando cada um destes elementos em uma mercadoria, ainda que fictícia (POLANYI, 1980, p.84-87). É a artificialidade da separação entre terra, trabalho e capital que permite ao direito agrário, a um só tempo se aproximar dos institutos clássicos do direito civil mas nunca se afastando dos demais ramos, como o constitucional e o administrativo. Não se trata de uma 
mera mistura entre diversos ramos do direito que versam sobre a atividade agrária, mas, em verdade, da criação de um ramo inteiramente novo, com método, dinâmica, princípios e objeto próprios. De certa forma, o direito agrário nasce da dialética.

A insuficiência do direito privado para tratar da questão também é notável. O direito civil, historicamente representado pelo Código Napoleônico, diminuía a discussão a respeito da terra a mera discussão de propriedade e de contratos, ignorando completamente o aspecto político e social que envolvem a posse e o cultivo da terra, além de outros problemas complexos, como a proteção da natureza e o direito à alimentação, que ganharam força após a Segunda Guerra Mundial.

É neste ponto que se nota as contribuições das novas Constituições para a formação do direito agrário moderno. Para Carrozza e Zeledón (1990, p. 143), as Constituições Mexicana (do ano de 1917) e de Weimar (alemã, de 1919) transformaram o panorama do constitucionalismo ocidental de um modelo essencialmente liberal e individualista, preocupado em defender a inviolabilidade do direito de propriedade, para um modelo social, preocupado em garantir os direitos e o bem-estar dos cidadãos ${ }^{4}$.

Além destes fatores, é necessário também estar atento ao que vinha acontecendo entre o final do século XIX e o início do século XX na Europa. Percebia-se a crescente influência do positivismo de Auguste Comte, e logo a ideia de progresso foi associada à de industrialização.Ao mesmo tempo, via-se a revolução industrial se consolidar no território italiano, trazendo consigo mecanização para o campo e a formação de um complexo industrial. Na seara econômica, vê-se o apogeu do modelo liberal e na política os conflitos que desencadearam a Primeira Guerra Mundial.

O modelo de desenvolvimento rural, naquele momento, era basicamente o mesmo desde o início do capitalismo nos campos ingleses (WOOD, 2000, p. 20): aumento de produtividade. Campo desenvolvido era campo lucrativo, que produzia muito gastando pouco. Assim, o Direito Agrário nasce dedicando pouca (ou nenhuma) atenção às formas pré-capitalistas de produção, menos preocupadas com a produtividade do que com a conservação dos costumes e 
preservação das estruturas da sociedades. Como se vê, o Direito Agrário nasce em uma típica sociedade industrial moderna.

Este padrão de desenvolvimento para o campo inaugurado pelo capitalismo e aprimorado com o desenvolvimento das sociedades industriais modernas nunca se inverteu. Ao contrário, aprimorou-se. Um reflexo disso é o conceito de empresa agrária, presente no Código Civil Italiano de 1942.Promulgado duas décadas após a fundação da Rivista de Diritto Agrario, o diploma passou a efetuar a interessante distinção entre empresa comercial e empresa agrária (TRENTINI, 2012, p.3). Desenvolvimento para o campo, no âmbito de uma sociedade industrial no auge dos esforços da segunda guerra, era sinônimo de produtividade, de altas quantidades de grãos providos em intervalos regulares. Para tanto foi necessário elaborar uma legislação específica, que trataria dessas novas empresas rurais.

O conceito de empresa rural se difundiu tanto na Europa quanto na América Latina e, ainda hoje, é um dos pilares do estudo do Direito Agrário. Com a formação dessas empresas agrárias, e a sucessiva incorporação de novas técnicas para o aumento da produtividade, também começa a aparecer o lado negativo da industrialização no campo: o aumento dos riscos associados aos avanços tecnológicos.

A chamada "revolução verde" (ou revolução agrícola), que ocorreu entre as décadas de 60 e 70, conjugado com as inovações da biotecnologias, entre o final dos anos 70 e início dos 80, trouxeram para a agricultura uma série de tecnologias que permitiram um rápido e amplo crescimento da produtividade agrícola no mundo ocidental. Como apurou Boaventura de Sousa Santos (2008, p. 291), “[...] entre 1950 e 1984, a produção agrícola mundial cresceu mais rapidamente do que em qualquer período anterior e a produção de cereais cresceu mais que a população."

Tratou-se, em um primeiro momento, de técnicas de melhoramento de sementes (hibridização), da criação de insumos artificiais (especialmente os fertilizantes e agrotóxicos) e de um novo maquinário para o campo. Em um segundo momento, chegou ao campo a biotecnologia, permitindo a criação dos organismos geneticamente modificados. Como conta Arnaud Zacharie (2008, 
p. 2), amparado por essas novas técnicas de produção, o Banco Mundial, a partir da década de 80 , passa a encorajar os países em desenvolvimento a abandonar as suas agriculturas de subsistência para se especializarem em alguns tipos de agricultura de alto rendimento, como o algodão ou o café, no intuito de obter fundos para o pagamento das dívidas externas. Nos países em desenvolvimento, como o Brasil, isso significou a intensificação do modelo de "latifúndios agroexportadores" baseados em monoculturas, e a manutenção do modelo de desenvolvimento produtivista.

Os riscos dessas novas tecnologias aplicadas à atividade agrícola já não se caracterizam mais como aqueles contraídos pelos Estados industrializados modernos, mas como riscos típicos das "sociedades de risco". Os danos provocados pela utilização abusiva dos insumos industrializados começam a ser sentidos: envenenamento dos solos e dos lençóis freáticos e destruição de fauna nativa. Ainda na década de 70, o DDT (Dicloro-Difenil-Tricloroetano), popular pesticida utilizado na agricultura, foi acusado de ser prejudicial à saúde humana e foi banido emuma série de países.

Ao mesmo tempo, o Banco Mundial começa a ouvir protestos de cunho ambiental, já que as suas diretrizes econômicas encorajam o aumento da derrubada das matas nativas dos países em desenvolvimento para a expansão do modelo de latifúndios agroexportadores. O mundo começava a perceber que os efeitos nocivos da degradação ambiental não estavam restritos às fronteiras dos Estados. Esses novos riscos ameaçam todo o globo igualmente.

Os riscos e consequências de algumas dessas novas tecnologias, ainda hoje, não foram devidamente estudados e avaliados. Como adverte Boaventura (SANTOS, 2008, p. 292), a biotecnologia, o melhoramento genético de espécies vivas, parece subordinar todo ganho de produtividade à destruição da biodiversidade. Mesmo a segurança da inclusão de alimentos transgênicos na dieta humana passa a ser questionada, uma vez que os estudiosos (sistema perito) não chegam a qualquer consenso sobre a matéria.

Por estes motivos, o modelo de desenvolvimento agrário baseado exclusivamente no aumento da produtividade passou a se mostrar extremamente nocivo ao ser humano. Como bem advertia Ulrich Beck, apesar 
de uma inicial distribuição dos riscos de acordo com classes ou extratos sociais, no final, as consequências dos riscos atingem todas as pessoas, inclusive aqueles que os criaram ou lucraram com eles.

\section{CONSIDERAÇÕES FINAIS}

O desafio do Direito Agrário contemporâneo, segundo Zeledón (2013, p. 32-33) é ser um Direito "AAA", ou seja, um direito preocupado com a agricultura, com o meio ambiente e com a alimentação. Como foi visto, 0 modelo de desenvolvimento das sociedades industriais modernas, nascido com o sistema capitalista, preocupou-se exclusivamente com o primeiro "A", a agricultura e a sua produtividade. Foi neste ambiente que nasceu o Direito Agrário, que inicialmente se preocupou apenas com a produção e a estruturação dessa produção dentro da burocracia estatal, pouco preocupado com os impactos, especialmente ambientais, de suas práticas.

Com a contínua incorporação de novas tecnologias ao processo produtivo, a agricultura, a partir da segunda metade do século $X X$, se tornou a mais produtiva de toda a história da humanidade mas, ao mesmo tempo, a mais destrutiva. As novas tecnologias da revolução verde e da biotecnologia certamente garantiram um aumento sem igual na quantidade de grãos produzidos, todavia, com um preço a pagar. Os riscos advindos desta "modernização" das técnicas agrícolas, que anteriormente eram limitáveis e só possuíam força para atingir determinados grupos de pessoas, tornaram-se ilimitados e indeterminados. A contaminação da água e dos solos, assim como a experiência genética em seres vivos não estão contidos em um espaçotempo, mas, ao contrário, afetam o globo como um todo. Da mesma forma, a devastação das matas nativas para a formação de latifúndios de exportação não prejudica apenas um Estado, mas toda a espécie humana.

Essas ameaças, típicas das sociedades de risco, começam a transformar os ideais de desenvolvimento agrário. O próprio Banco Mundial, anteriormente ferrenho defensor do desenvolvimento agrário da modernidade, no ano de 2008 lançou um "new deal' para a alimentação mundial que, em linhas curtas, baseava-se no estímulo à agricultura de subsistência. Trata-se de 
um modelo de produção que utiliza com moderação insumos agrícolas industrializados, geralmente utiliza as sementes de colheitas anteriores para 0 próximo plantio (não utilizando, em regra,transgênicos) e mais respeitosas com o meio ambiente ao seu redor. O que o Banco Mundial pediu, na realidade, é um novo modelo de agricultura, que consiga diminuir os efeitos devastadores que o modelo de agricultura "moderno" acarretou.

Por este motivo que o direito agrário moderno, antes de tudo, é um Direito Agrário em reformulação. É um ramo do Direito que busca conciliar a produtividade na agricultura com a defesa do meio ambiente e das populações que dela vivem. Institutos classicamente modernos, como de "empresa rural" e "agronegócio" agora devem conviver com a agricultura de subsistência e a familiar, assim como observar a cuidados ambientais. Como se denota no título da obra de Giddens, o desafio do Direito Agrário atual é conviver com "as consequências da modernidade".

\section{NOTAS EXPLICATIVAS}

1. "Dicho de otro modo, desde mediados del siglo XX las instituciones sociales de la sociedad industrial se han enfrentado a la possibilidad, históricamente sin precedentes, de la destruicción de toda vida en el planeta a través de las decisiones que se tomem." (BECK, 2002, p. 83)

2. "En tercer lugar, el "accidente" pierde su delimitacíon em el tiempo y en el espacio, y con ello su significado. Se convierte en un suceso con um principio pero sin fin: um 'festival abierto' de oleadas de destruccíon progresivas, galopantes y solapadas. Lo que esto implica es la abolición de los estándares de normalidad, de los procedimientos de evaluación y, por tanto, de la base del cálculo de los peligros; se comparan entidades incomparables y el cálculo se convierte en ofuscación." (BECK, 2002, p. 84).

3. A biblioteca virtual de Direitos Humanos da Universidade de São Paulo (USP) disponibiliza gratuitamente trechos selecionados e traduzidos do Código de Hamurabi. Disponível em: http://www.direitoshumanos.usp.br/index.php/Documentos-anteriores- 
\%C3\%A0-cria\%C3\%A7\%C3\%A3o-da-Sociedade-das-Na\%C3\%A7\%C3\%B5esat\%C3\%A9-1919/codigo-de-hamurabi.html Último acesso: 23 de julho de 2013.

4. No aspecto agrário, a atual Constituição brasileira é um bom exemplo de fruto desta mudança constitucional exposta pelos juristas. No inciso XXIII de seu artigo $5^{\circ}$, determina que "a propriedade atenderá a sua função social". Vale lembrar que a própria Constituição, em seu artigo 182, estabelece quais são os requisitos que devem ser observados para cumprir a função social da terra: 0 "aproveitamento racional e adequado", a "utilização adequada dos recursos naturais", a "preservação do meio ambiente", a obediência à legislação trabalhista e, finalmente, um modelo de exploração que favoreça o bem-estar não apenas dos proprietários, mas também dos trabalhadores. Todos estes valores extrapolam visivelmente discussões restritas à propriedade ou contratos, entretanto, são fundamentais para se entender o direito agrário moderno.

\section{REFERÊNCIAS}

BECK, Ulrich. La sociedade del riesgo global. España: Siglo Veintiuno, 2002.

Sociedade de risco: Rumo a uma outra modernidade. Trad. Sebastião Nascimento. São Paulo: Editora 34, 2010.

CARROZZA, Antonio; ZELEDÓN, Ricardo Zeledón. Teoría general e institutos de derecho agrario. Buenos Aires: Editorial Astrea, 1990.

GIDDENS, Anthony. As consequências da modernidade. Trad. Raul Fiker. São Paulo: Editora Unesp, 1991.

LÖWY, Michael. Ecologia e socialismo. São Paulo: Cortez, 2005.

MANIGLIA, Elisabete. As interfaces do Direito Agrário e dos Direitos Humanos e a Segurança Alimentar. São Paulo: Cultura Acadêmica, 2009.

POLANYI, Karl. A Grande Transformação: as origens de nossa época. Trad. Fanny Wrobel. 3. Ed. Rio de Janeiro: Campus, 1980.

SANTOS, Boaventura de Sousa. Pela Mão de Alice: O social e o político na pós-modernidade. 12. ed. São Paulo: Cortez, 2008.

SEN, Amartya. Desenvolvimento como liberdade. Trad. Laura Teixeira Motta. São Paulo: Companhia das Letras, 2010. 
TRENTINI, Flávia. Teoria Geral do Direito Agrário Contemporâneo. São Paulo: Editora Atlas S.A, 2012.

WOOD, Ellen Meiksins. As origens agrárias do capitalismo. Revista Crítica Marxista, n. 10, ano 2000, São Paulo: Boitempo. p. 12-30.

ZACHARIE, Arnaud. Ebullitions sociales et crises alimentaires. 21 de abril de 2008. Disponível em: <http://www.cetri.be/spip.php?article566\&lang=fr>. Último acesso: 28 de julho de 2013.

ZELEDÓN, Ricardo Zeledón. Derecho Agrario Contemporáneo. 2. ed. Rev. At. Curitiba: Juruá Editora, 2013. 